\title{
INTENSE BEAMS: THE PAST, PRESENT, AND FUTURE*
}

$$
\text { G. Yonas, M. A. Sweeney SAND }-98-1286 \mathrm{C}
$$

Sandia National Laboratories, Albuquerque, NM 87185-0151

\section{INTRODUCTION}

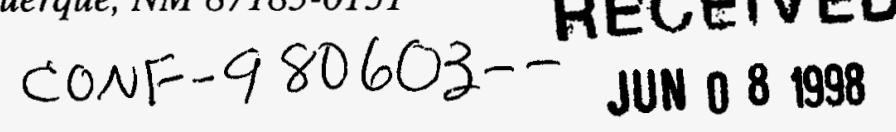

Nobody could have predicted the circuitous course of the last 30 years of progress in intense beams and pulsed power. There were many discoveries and twists and turns along the way, but the steady flow of understanding and technological advances has sustained the field. Pulsed power research began in the early 1960s with the development of the technology to test the reliability of nuclear weapons in a pulsed radiation environment. Because of the effort in the 1970s on an electron beam approach to inertial confinement fusion (ICF) at Sandia National Laboratories and at the Kurchatov Institute, simulation codes, diagnostics, and innovative pulsed power techniques such as self-magnetic insulation were developed. The electron approach ended in 1979, and the more promising ion approach continued. At the same time, $\mathrm{z}$ pinches, used since the early 1970 s to evaluate the response of materials to $\mathrm{keV} x$ rays, were considered as an alternative to drive ICF capsules. The use of $\mathrm{z}$ pinches for ICF was discontinued in 1984 because of budget cuts and the belief that ions offered a route to the standoff requirement for energy applications. Now, in 1998, because of budget limitations and the 1995 discovery that the soft $\mathrm{x}$-ray power achievable in a z-pinch implosion can be greatly enhanced, the ion approach has been suspended, and a new facility, X-1, proposed to achieve high yield in the laboratory with z pinches.

In this paper we review the research paths that led to these changes, describe the present status of $\mathrm{z}$ pinches, and predict what the future holds. Although nobody can predict the future, the past 30 years have taught us some lessons that can be applied to the next 30 years. The paper concludes with some of these "lessons learned."

\section{THE PAST}

\section{DISTRIBUTION OF THES DOCUMENT IS UNE.IMITED}
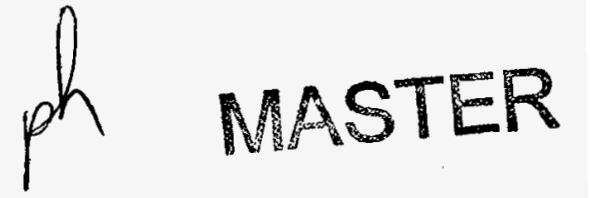

Intense beam research is based on pulsed power capabilities developed to provide bremsstrahlung sources of short duration for testing the resistance of weapons components to nuclear radiation bursts at what is now called the Atomic Weapons Establishment in Aldermaston, England, under Charlie Martin. ${ }^{1}$ There, a series of ideas led to the first pulsed power accelerator, SMOG, in 1964 and formed the basis of the prolific international pulsed-power technology that exists today and includes research at Sandia, Cornell, Naval Research Laboratory (NRL), Physics International (PI), Maxwell Technologies, the Blackett Laboratory at Imperial College, Forschungszentrum at Karlsruhe, the Institute of Laser Engineering at Osaka, the Institute of High Current Electronics, Kurchatov, Arzamas, and the Triniti Institute.

In the United States, pulsed power technology has mainly been funded by the Department of Energy and the Defense Special Weapons Agency. Short-pulse energy storage devices at Sandia during this early period (SPASTIC, Hermes I and II, Nereus, Hydra) produced an electron beam at the cathode when small whiskers exploded as the diode current increased, or an $\mathrm{x}$-ray source to provide high-dose-rate radiation for weapons effects testing and to assess the response of materials to rapid energy deposition.

*This work is supported by the U.S. Department of Energy contract DE-AC04-94-AL85000. 
Figure 1. Timeline showing highlights in intense beams and pulsed power technology, beginnning with operation of the first submicrosecond pulsed power device in 1964.

Energy in the pulsed power accelerator is taken slowly from local power grids, stored in a bank of high-voltage capacitors, called a Marx, and compressed in time in a coaxial pulseforming line using a high-speed switch to get high power. Power is then compressed in space in the accelerator center to get high power density. Over the years, the problem of transporting the electromagnetic energy at increasingly higher power density has been addressed by improved design of pulse-forming components, selection of dielectrics of higher breakdown strength, use of self-magnetically-insulated transmission lines, and laser triggering to synchronize pulses in separate, azimuthally-arranged modules. Technological advances have occurred since completion of PBFA II, the largest pulsed power accelerator, in 1985. One of the most significant of these is the efficient, compact, and versatile linear voltage addition in the water sections of Hermes III and SABRE.

In a pulsed power accelerator, electrons or ions are produced by forming a plasma between two electrode surfaces and accelerating the particles across a small inter-electrode gap. Specific geometry and magnetic field configurations produce electron flow or, instead, suppress this flow using a "virtual cathode" that enhances the flow of ions and, with space charge and current neutralization, allows ions to propagate ballistically or in a current-carrying channel to a target.

In the early 1970 s, it was recognized that the electrons could be concentrated to high enough intensities for ICF. $^{2}$ In $1976,10^{6}$ fusion neutrons were obtained on Angara at Kurchatov by heating a gold foil with reflexing electrons. The following year, Sandia obtained fusion neutrons from the " $\Phi$ target" on REHYD, by electrical breakdown along a $C_{2}$ wire embedded in a capsule that both preheated the fuel and established a magnetic field to reduce energy losses during the implosion. ${ }^{11}$ Also, at NRL and Sandia, electron beams were propagated several meters to a target in a plasma channel containing a strong magnetic field. Soon, however, it was recognized that ions have better properties for igniting the fuel because of their shorter range in materials and the absence of bremsstrahlung that can degrade the fuel compression. In 1968 Graybill and Young at Ion Physics Corporation discovered, for low $v_{\mathrm{e}} / \gamma_{\mathrm{e}}$ beams, that the collective effects of a large number of electrons could be used to accelerate a smaller number of ions to high energies; during the 1970s these studies were extended to high $\nu_{\mathrm{e}} / \gamma_{\mathrm{e}}$ beams. ${ }^{10}$ Nevertheless, until the late 1970 s, efficient ways to produce intense ion beams had not been devised. Then, rapid progress at Cornell, Sandia, and NRL changed the program emphasis from electrons to light ions, and facility development underway to produce electrons 


\section{DISCLAIMER}

This report was prepared as an account of work sponsored by an agency of the United States Government. Neither the United States Government nor any agency thereof, nor any of their employees, makes any warranty, express or implied, or assumes any legal liability or responsibility for the accuracy, completeness, or usefulness of any information, apparatus, product, or process disclosed, or represents that its use would not infringe privately owned rights. Reference herein to any specific commercial product, process, or service by trade name, trademark, manufacturer, or otherwise does not necessarily constitute or imply its endorsement, recommendation, or favoring by the United States Government or any agency thereof. The views and opinions of authors expressed herein do not necessarily state or reflect those of the United States Government or any agency thereof. 
(PBFA I) was reoriented to produce ions. The more promising ion approach grew and continued as we learned more about diagnostics, theory, instabilities, and beam propagation. ${ }^{3}$

At the same time as the emergence of the ion approach, $\mathrm{z}$ pinches, which had been produced since the early 1970 s as an energetic source of $\mathrm{keV}$ x rays, ${ }^{4}$ were examined as a way to generate soft $x$ rays to drive a capsule. When the z-pinch approach died because of the standoff needed for energy applications, two parts continued--photon-pumped x-ray laser research for the Strategic Defense Initiative and K-shell x-rays for radiation effects. Researchers at that time tried to maximize the $\mathrm{x}$-ray energy from pinches, rather than maximizing $\mathrm{X}$-ray power as we are doing now, by driving hollow gas puffs, thin metal foils, or a few wires on Proto II and Saturn at Sandia, on Double Eagle at PI, and on Blackjack 5 at Maxwell. Then, in the early 1990 s, the impending cessation of underground testing created a need to test the predictions of simulation tools over a broad range of x-ray pulse widths and energies to guarantee the safety and reliability of nuclear weapons. A 1994 "PBFA Z" project ${ }^{5}$ to design a z-pinch version of PBFA II to fill in existing gaps in radiation effects testing then led to the discovery in 1995 on Saturn that many fragile wires, rather than just a few, ${ }^{6}$ strung on spool-sized hardware could greatly enhance the soft x-ray power output. ${ }^{7}$

The major issues for ions were whether the electromagnetic energy could be converted efficiently to a single-species ion beam and whether that beam could be focused onto a hohlraum at a sufficient intensity to generate $\mathrm{x}$ rays that would then compress a capsule. Unfortunately, the high ion current causes collective effects that defocus the beam unless electromagnetic instabilities are carefully controlled. Particle-in-cell simulations have demonstrated that high magnetic fields and metal limiters can be used to keep the instability in the less damaging, high-frequency diocotron mode for which the ion divergence does not grow. A 15-mrad beam divergence was obtained in 1984 for protons on Proto I and, the following year, these experiments were successfully scaled to the higher current and larger diode on PBFA I. Sandia, Cornell, and Osaka experiments indicated that the beam divergence would decrease with an increase in ion mass and lithium had an optimal range, so PBFA II was designed for singly-charged lithium. However, the lithium power density has not yet exceeded $2 \mathrm{TW} / \mathrm{cm}^{2}$, although scaling from the $1.5 \mathrm{TW} / \mathrm{cm}^{2}$ and $5 \mathrm{TW} / \mathrm{cm}^{2}$ achieved with protons on PBFA I and PBFA II, respectively, had predicted $100 \mathrm{TW} / \mathrm{cm}^{2}$ on PBFA II with lithium, even without a decrease in divergence. Difficulties have been encountered with achieving a high-purity, uniform, preformed lithium ion beam via a variety of active sources (the Laser EVaporation Ion Source, or LEVIS, the Laser Ionization Based on Resonant Saturation, or LIBORS, source or the Electrohydrodynamic, or EHD, source) in spite of using high magnetic fields, discharge cleaning, and anode heating to remove contaminant ions resulting from thermal and stimulated desorption of the anode surface and subsurface layers.

\section{THE PRESENT}

In 1998, because of budget limitations and discovery of the more promising approach using wire arrays, the tables have turned, with the ion vs $\mathrm{z}$ pinch decision of 1984 reversed and the ion approach suspended. Since the first z-pinch radiation shot on $\mathrm{Z}$ (the renamed z-pinch modification of PBFA II) in October 1996, an X-ray power of $290 \mathrm{TW}^{8}$ has been achieved on Shot 179 (Fig. 2), our understanding of the role of magnetohydrodynamic instabilities in the z-pinch implosion process has increased, x-ray yields for effects testing have increased an order of magnitude (Fig. 3) and, as shown in Table 1, four milestones have been exceeded (150 TW, $1.5 \mathrm{MJ}, 100 \mathrm{eV}$ in a static hohlraum, $150 \mathrm{eV}$ in an imploding hohlraum). Diagnostics added to $\mathrm{Z}$ include an end-on $\mathrm{x}$-ray pinhole camera to provide time- and energy-resolved 
images of the imploding plasma, a time-integrated, space-resolved crystal spectrometer, and a velocity interferometer to provide a measure of hohlraum temperature that is independent of the more traditional XRD- and spectrometer-based data. With the application of a concept, developed by the ICF community and tested on Livermore's Nova laser, of using a hohlraum to contain the soft $\mathrm{x}$ rays, ${ }^{9} \mathrm{Z}$ is now used for weapons physics experiments that were previously limited to high-power lasers. And, with recent increases in hohlraum temperature to $>150 \mathrm{eV}, \mathrm{Z}$ is becoming a route to the $\mathrm{X}-1$ concept for high yield and for simulating the entire cold $(<10 \mathrm{keV})$ and warm $(>10 \mathrm{keV}) \mathrm{x}$-ray environment. The latest turn of events is scaling of the design of the National Ignition Facility target concept to X-1 conditions.

Table 1: Achieved pulsed power milestones for $\mathrm{Z}$ performance

\begin{tabular}{|l|c|c|l|}
\hline \multicolumn{1}{|c|}{ milestones } & $\begin{array}{c}\text { required } \\
\text { value }\end{array}$ & $\begin{array}{c}\text { achieved } \\
\text { value }\end{array}$ & \multicolumn{1}{|c|}{$\begin{array}{c}\text { date } \\
\text { achieved }\end{array}$} \\
\hline \hline x-ray energy & $1.5 \mathrm{MJ}$ & $2.0 \mathrm{MJ}$ & $\begin{array}{l}\text { Nov. 1996, 1.8 MJ } \\
\text { Mar. 1997, 2 MJ }\end{array}$ \\
\hline x-ray power & $150 \mathrm{TW}$ & $290 \mathrm{TW}$ & $\begin{array}{l}\text { Nov. 1996, 200 TW } \\
\text { Jan. 1998, 290 TW }\end{array}$ \\
\hline $\begin{array}{l}\text { hohlraum } \\
\text { temperature for } \\
\text { weapon physics }\end{array}$ & $100 \mathrm{eV}$ & $150 \mathrm{eV}$ & $\begin{array}{l}\text { Apr. 1997, 100 eV } \\
\text { Oct. 1997, 140 eV } \\
\text { Apr.1998, 150 eV }\end{array}$ \\
\hline $\begin{array}{l}\text { hohiraum } \\
\text { temperature for } \\
\text { capsule compression }\end{array}$ & $150 \mathrm{eV}$ & $155 \mathrm{eV}$ & $\begin{array}{l}\text { Aug.- Sept. 1997, 140 eV } \\
\text { Mar. 1998, 155 eV }\end{array}$ \\
\hline
\end{tabular}

Figure 2. Progress in increasing the power radiated from wire-array $z$ pinches. The 25 years of progress, with large advances in the last two years, are based on an evolution from single-wire experiments to complex-multiple-wire, nested array experiments possible with the present highcurrent accelerators and from comparatively simple analysis of radiation sources to modeling the interaction of the magnetic fields, the radiation, and the moving plasma with high-performance computers.

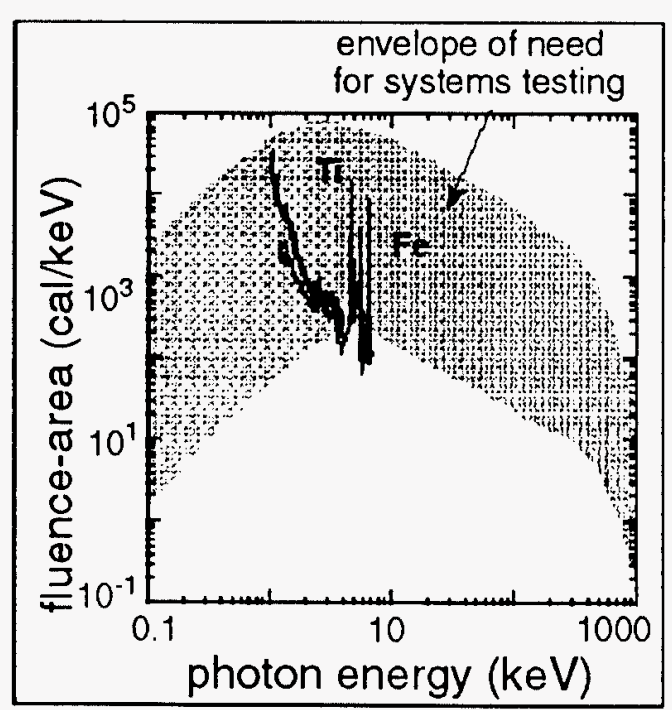

Figure 3. Fluence-area vs energy data from $Z$ for two materials, titanium and iron, plotted with respect to the envelope of need for weapons effects testing of non-nuclear components. Warm (>10 keV) $x$-ray regime would be addressed with the proposed 60-MA $X-I$ facility. 


\section{THE FUTURE}

This admittedly incomplete recounting of past history shows that optimism and perseverance, along with innovation and creativity, are necessary virtues for people in this field. In this spirit, we can predict that, by continuing in the path of the past 30 years, and with expanded cooperation with universities, industry, and government laboratories around the world, in the not too distant future, we can achieve the first high-yield fusion conditions in a laboratory on $\mathrm{X}-1$ by 2010 and then go on to begin a fusion power plant exploration beginning in 2020 and, perhaps, to practical energy applications by the middle of the next century, if a method can be devised to allow standoff with $\mathrm{z}$ pinches or with some combination of ions and pinches. The design for X-1 should be flexible enough to fulfill three objectives: a high-yield fusion output of 200 to $1000 \mathrm{MJ}$ to address the long-term mission of the National ICF program, a flexible, well-characterized source for weapons physics applications, and a cold $(<10 \mathrm{keV})$ and warm (10 to $80 \mathrm{keV}$ ) $\mathrm{x}$-ray environment for radiation effects testing.

Complex technical problems remain to be solved. One is whether a factor of three higher current $(60 \mathrm{MA})$ can be crammed into the same size hohlraum as used on $\mathrm{Z}\left(5 \mathrm{~cm}^{3}\right)$. The reason this enormous concentration of power into small cavities works--magnetic insulation--was discovered almost 30 years ago at Kurchatov, PI, and Sandia. Recently, a gap of $1.5 \mathrm{~mm}$ between the wires and the hohlraum wall, compared to the conservative 5-mm gap we started with, has stayed open, allowing further increases in the energy coupled into $\mathrm{x}$ rays and decreases in radiation losses. Other issues are whether the efficiency of conversion to $\mathrm{x}$ rays remains at the $15 \%$ level seen on $\mathrm{Z}$, whether instabilities remain under control, and whether we can achieve the symmetry and shape of the radiation pulse onto the capsule that computer simulations suggest are needed. The $\mathrm{z}$-pinch loads on $\mathrm{X}-1$ will require more massive wires or a return to the use of foils, but with the preferential vertical current flow direction embedded in the foils, and, perhaps, the design of a more spherically symmetric z-pinch load.

At present, the expectations for future commercial applications are higher for deeper penetrating hard $\mathrm{x}$-rays and particle beams than for soft $\mathrm{x}$-rays. The pulsed beam applications would include destruction of organic wastes, large-scale food sterilization, and low cost surface treatment of materials. However, intense soft $\mathrm{x}$ rays can be expected to provide practical tools for novel applications such as the ability to study features in the several hundred angstrom range in physical materials and biological samples and a lithographic technique to imprint submicron-scale electronic circuit patterns on silicon memory chips. And, with the techniques being developed on $\mathrm{Z}$, biologists may be able to observe the structure and dynamic processes of living cells at high spatial resolution over nanosecond time periods.

\section{LESSONS LEARNED}

Nobody can predict or control the future, but optimism and perseverance are likely to carry the day when the research foundations are valid. What are some of the lessons that we have learned in the past 30 years that can be applied in the next 30 ?

- Mother nature is a hard task master, and difficult problems such as stockpile stewardship and fusion demand enormous patience, dedication, innovation, and skill.

- We learn by a gradual increase in knowledge that is gained by the efforts of many people at various stages in their careers and with various educational backgrounds who practice their craft in a large variety of research settings. The open sharing of information--locally, nationally, and internationally--is the best way to make progress.

- Empirical discoveries happen, and we must be alert to notice them and to understand what 


\section{GY 6}

these serendipitous discoveries are telling us about the next step to take.

- Government funding of basic research plays an irreplaceable role in this process. Experience in industry and in the national laboratories has shown that private industry would not be able to pick up the slack if this government funding were not provided. Government funding, particularly in the early stages, allows researchers not just to stick with the "sure thing" but to engage in risky, but innovative, research that leads to practical applications. Basic scientific research is underfunded everywhere and that fact should be, and is, driving more and more cooperation. The problem is how to make that happen while still having open competition that brings out the best in everyone. The answer is to both cooperate and to compete.

\section{REFERENCES}

[1] J. C. Martin on Pulsed Power, ed. T. H. Martin, A. H. Guenther, M. Krisiansen (Plenum Press, NY, 1996).

[2] G. Yonas, Scientific American 239, pp. 50-61 (1978).

[3] T. A. Mehlhorn, IEEE Transactions on Plasma Science 25, pp. 1336-1356 (1997).

[4] N. R. Pereira, J. Davis, Journal of Applied Physics 64, pp. R1-R27 (1988).

[5] R. B. Spielman, et al, Proc. IIth Intl. Conf. on High Power Particle Beams, ed. K. Jungwirth, J. Ulischmied (Institute of Plasma Physics, Prague, 1996), pp. 150-153.

[6] C. Stallings, K. Nielsen, R. Schneider, Applied Physics Letters 29, pp. 404-406 (1976).

[7] M. K. Matzen, Physics of Plasmas 4, pp. 1519-1527 (1997).

[8] R. B. Spielman, et al, Physics of Plasmas 5, 2105 (1998).

[9] J. D. Lindl, Physics of Plasmas 2, pp. 3933-4024 (1995).

[10] C. L. Olson, "Collective Ion Acceleration with Linear Electron Beams," in Springer Tracts in Modern Physics: Collective Ion Acceleration (Springer-Verlag, NY, 1979), vol. 84, pp. 1-144.

[11] J. S. T. Chang, et al, Proc. 2nd Intl. Top. Conf. on High Ppower Electron and Ion Beam Research and Technology (Cornell University, NY, 1978), vol. 1, p. 195.

[12] Mazarakis, beam propagation in air?

M. G. Mazarakis, R. B. Miller, J. W. Poukey, R. J. Adler, "IBEX Magnetic-Field Extraction and Propagation Experiments of Intense High-Energy Electron Beams," Journal of Applied Physics 62, 4024 (1987).

[13] R. B. Miller, beam propagation in laser ionization channel.

[14] C. Deeney, et al, "Scaling of above $4 \mathrm{keV}$ X-ray Sources to $100 \mathrm{~kJ}$ Yields from the "Z" Accelerator," 39th Annual Meeting of the Division of Plasma Physics, Pittsburgh, PA, 17-21 November 1997; to be submitted to Physics of Plasmas.

[15] J. E. Maenchen, "Inductive Voltage Adder Driven Flash Radiography," 1998 American Physical Society/ American Association of Physics Teachers Joint April Meeting, Columbus, Ohio, April 18-21, 1998 (invited talk). production of an intense, focused (1-mm spot size) electron beam for radiography at high current and voltage (100s of $\mathrm{kA}$, up to $20 \mathrm{MV}$ ) using modular components and a strong (10 to 50 tesla) axial magnetic field... 


$$
\text { Report Number (14) } \frac{\text { SAND }-98-1286 \mathrm{C}}{\text { CONF }-980603 \cdots}
$$

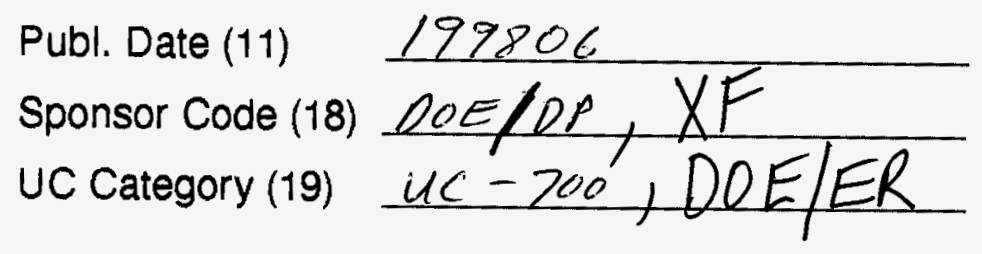

$$
19980706083
$$

